\title{
Comparative study of ozonation and synthetic goethite-catalyzed ozonation of individual NOM fractions isolated and fractionated from a filtered river water
}

\author{
Tao Zhang ${ }^{a}$, Jinfeng $\mathrm{Lu}^{a}$, Jun $\mathrm{Ma}^{a, *}$, Zhimin Qiang $^{b}$ \\ aschool of Municipal \& Environmental Engineering, Harbin Institute of Technology, Harbin 150090, China \\ ${ }^{\mathrm{b}}$ Research Center for Eco-Environmental Sciences (RCEES), Chinese Academy of Sciences, Beijing 100085, China
}

\section{A R T I C L E I N F O}

\section{Article history:}

Received 14 August 2007

Received in revised form

31 October 2007

Accepted 7 November 2007

Available online 17 November 2007

Keywords:

NOM fractions

Ozonation

Synthethic goethite-catalyzed

ozonation

Oxidation by-products

Molecular weight distribution

Filtered water

\begin{abstract}
A B S T R A C T
This study comparatively investigated ozonation and synthetic goethite-catalyzed ozonation of individual natural organic matter (NOM) fractions in terms of ozone consumption, dissolved organic carbon (DOC) and UV-absorbance reduction, molecular weight (MW) distribution, and formation of low-MW oxidation by-products. Hydrophobic acid and neutral (HOA and HON) and hydrophilic acid and base (HIA and HIB) were four major NOM fractions isolated from a filtered river water; so ozonation and catalytic ozonation were carried out on these fractions. Results indicate that in comparison to ozonation alone, catalytic ozonation can enhance ozone consumption, $\mathrm{UV}_{254}$ and DOC reduction, fragmentation of fraction components with $\mathrm{MW}>3000 \mathrm{Da}$, and formation of oxalic acid for these fractions under normal reaction conditions commonly adopted in water treatment plants. In addition, catalytic ozonation can enhance aldehydes formation and increase the percentage of easy biodegradable organic carbon compared with ozonation alone for HIA and HIB, but exert much less effect on these items for HOA and HON.
\end{abstract}

c) 2007 Elsevier Ltd. All rights reserved.

\section{Introduction}

Catalytic ozonation with metal oxides, as an alternative technique to ozonation alone to improve the decomposition of recalcitrant organic pollutants in water treatment, has received increasing attention in recent years. The mechanism of this technique can be ascribed to catalytically enhanced hydroxyl radical generation from aqueous ozone (Ma and Graham, 2000; Lim et al., 2001), formation of metal-pollutant complexes which react fast with molecular ozone (Park et al., 2004a; Beltrán et al., 2005), or simultaneous adsorption of both pollutants and ozone on catalyst surfaces (KasprzykHordern et al., 2003). Most researches on catalytic ozonation were aimed to remove target refractory pollutants (KasprzykHordern et al., 2003). However, these pollutants are usually present at trace concentrations (e.g., several to tens of $\mu \mathrm{gL}^{-1}$ ) in natural surface waters, thus only representing an insignificant portion of dissolved organic carbon (DOC). Natural organic matter (NOM) dominates the DOC even after the surface water is coagulated and sand-filtered. It is known that NOM is the precursor of disinfection by-products and the nutrients source for bacteria reproduction in water distribution systems (Griffini et al., 1999; Singer, 1999). Therefore, it is necessary to elucidate the impact of catalytic ozonation on NOM besides the enhanced degradation of the refractory pollutants. Up to date, there are only limited reports on this topic. Catalytic ozonation with $\mathrm{TiO}_{2}$ was found to be able to improve the reduction of TOC and UV absorbance for surface waters (Gracia et al., 2000). Catalytic ozonation of concentrated NOM of river water and tap water with commercial

\footnotetext{
*Corresponding author. Tel.: +86451 86282292; fax: +8645182368074.

E-mail addresses: taozhang@rcees.ac.cn (T. Zhang), majun@hit.edu.cn (J. Ma).
} 0043-1354/\$ - see front matter @ 2007 Elsevier Ltd. All rights reserved. doi:10.1016/j.watres.2007.11.005 
goethite and alumina could also improve TOC reduction and NOM fragmentation (Park et al., 2004b; Kasprzyk-Hordern et al., 2006). As a complex mixture, the aquatic NOM components can be fractionated into different hydrophobic/ hydrophilic fractions in a wide range of molecular weight (MW) (Leenheer, 1981). These NOM fractions usually have different reactivity toward oxidants such as ozone and chlorine dioxide (Świetlik et al., 2004). Therefore, it is needed to investigate the impact of catalytic ozonation on individual NOM fractions to obtain an improved understanding of reaction mechanisms. Since catalytic ozonation is generally applied as an advanced treatment process after sand filtration and prior to chlorine disinfection in water treatment, it is especially necessary to carry out the study on catalytic ozonation of individual NOM fractions isolated from the filtered water under normal reaction conditions (e.g., conventional ozone dosage and reaction time).

Goethite can promote aqueous ozone decomposition and enhance the generation of hydroxyl radicals (Lim et al., 2001), which is ascribed to the interaction of its surface hydroxyl groups and ozone under neutral water $\mathrm{pH}$ conditions (Zhang and Ma, 2007). Goethite is a suitable catalyst for ozonation, because it has not only a highly hydroxylated surface but also a very low water solubility $\left(K_{\mathrm{sp}}=3 \times 10^{-39}\right)$ when suspended in water. This study was to examine the effect of synthetic goethite-catalyzed ozonation on individual NOM fractions in terms of ozone consumption, DOC and UV-absorbance reduction, MW distribution, and formation of low-MW carbonyl and carboxyl by-products. The individual NOM fractions were isolated from the filtered water of a conventional water treatment plant whose source water is from Songhua River. Experiments were carried out under normal reaction conditions (e.g., ozone dosage, $\mathrm{pH}$ condition, and reaction time) commonly applied in water treatment plants.

\section{Experimental methods}

\subsection{NOM isolation and fractionation}

Since catalytic ozonation is generally applied after filtration and before chlorination as an advanced water treatment process, the filtered water of a water treatment plant was used for NOM isolation in this study. In this plant, the source water from Songhua River at the upstream of Harbin was treated successively with aluminum sulfate coagulation, sand filtration, and membrane filtration with MW cut-off of $50 \mathrm{kDa}$, in which processes DOC of the water was reduced from 4.34 to $3.31 \mathrm{mgL}^{-1}$. The procedures developed by Leenheer (1981) and Świetlik et al. (2004) were employed in NOM isolation and fractionation with minor modifications. About $500 \mathrm{~L}$ of the filtered water were pumped consecutively through $500 \mathrm{~mL}$ of $\mathrm{XAD}-8$ and $300 \mathrm{~mL}$ of XAD-4 Amberlite resins at a flow rate of $60 \mathrm{~mL} \mathrm{~min}^{-1}$. Hydrophobic base (HOB) was eluted from XAD-8 with $400 \mathrm{~mL}$ of $0.1 \mathrm{M} \mathrm{HCl}$ and $400 \mathrm{ml}$ of $0.01 \mathrm{M} \mathrm{HCl}$ in sequence at a flow rate of $20 \mathrm{~mL} \mathrm{~min}^{-1}$. The effluent from XAD-8/XAD-4 was adjusted to $\mathrm{pH} 2$ with concentrated $\mathrm{HCl}$ and consecutively passed through the two resins again. The process was controlled by DOC measurement in the effluent and was discontinued when DOC concentration exceeded $1 \mathrm{mgL}^{-1}$.
After rinsing the XAD-8 with $400 \mathrm{~mL}$ of $0.01 \mathrm{M} \mathrm{HCl}$ and $400 \mathrm{~mL}$ of distilled water at $20 \mathrm{~mL} \mathrm{~min}^{-1}$, hydrophobic acid (HOA) was eluted from the resin with $1.0 \mathrm{~L}$ of $0.1 \mathrm{M} \mathrm{NaOH}$ and $0.5 \mathrm{~L}$ of distilled water at the same flow rate. Then, the XAD- 8 resin was dried at $50^{\circ} \mathrm{C}$ for $24 \mathrm{~h}$ before being Soxhlet-extracted with methanol. Hydrophobic neutral (HON) was eluted from the resin with methanol. The methanol was removed thereafter from the extract by vacuum evaporation at $60^{\circ} \mathrm{C}$ to obtain dried HON. The mixture of hydrophilic fractions was desorbed from the XAD-4 resin by sequential elutions with $1.0 \mathrm{~L}$ of $0.1 \mathrm{M} \mathrm{NaOH}$ and $500 \mathrm{~mL}$ of distilled water at $20 \mathrm{~mL} \mathrm{~min}^{-1}$. Then, the mixed eluate was acidified to $\mathrm{pH} 2$ with concentrated $\mathrm{HCl}$ and passed through $300 \mathrm{~mL}$ of AG-MP-50 resin and $300 \mathrm{~mL}$ of Duolite A-7 resin consecutively. To ensure sufficient adsorption, the effluent was circulated through the columns of the above two resins respectively at a gravity flow rate of $20 \mathrm{~mL} \mathrm{~min}^{-1}$ for 5 times. The final effluent was collected as hydrophilic neutral (HIN). Hydrophilic base (HIB) was retained on the cation-exchange resin, AG-MP-50, and hydrophilic acid (HIA) was adsorbed on the anion-exchange resin, Duolite A-7. HIB was eluted from AG-MP-50 with $500 \mathrm{~mL}$ of $1.0 \mathrm{M} \mathrm{NH}_{4} \mathrm{OH}$ at $20 \mathrm{~mL} \mathrm{~min}^{-1}$, while HIA was eluted from Duolite A-7 by $500 \mathrm{~mL}$ of 3.0 $\mathrm{M} \mathrm{NH}_{4} \mathrm{OH}$. All of these fractions except $\mathrm{HON}$ were dried with vacuum evaporation at $40^{\circ} \mathrm{C}$.

The total DOC of these isolated NOM fractions accounted for $80.1 \%$ of the original DOC of the filtered water. HOA, HON, HOB, HIA, HIN, and HIB occupied 49.6, 46.1, 0.4, 2.5, 0.2, and $1.2 \%$ of the isolated NOM in terms of DOC, respectively. The percentages of HOB and hydrophilic fractions were quite low, which is similar to that reported by Świetlik et al. (2004) for a filtered water. However, the HON content of the water is quite high compared to that reported by other researchers such as Świetlik et al. (2004) and Korshin et al. (1997). Since the percentages of NOM fractions of different water sources varied significantly (Leenheer, 1981; Korshin et al., 1997), this difference is probably ascribed to different waters used for DOM isolation and fractionation. The major NOM fractions (i.e., HOA, HON, HIA, and HIB) were selected for the experimental study here.

\subsection{Catalyst preparation and characterization}

Goethite (FeOOH) was synthesized following a method developed by Kandori et al. (1991). Ferric nitrate was precipitated with sodium hydroxide followed by aging the precipitate at $\mathrm{pH}>12$ for more than $48 \mathrm{~h}$. Then, alkaline was removed from the precipitate by repeated rinses with Milli-Q water until the $\mathrm{pH}$ of the rinsing water remained constant. The precipitate was finally dried at $120^{\circ} \mathrm{C}$ for $24 \mathrm{~h}$. It was confirmed to be pure goethite with X-ray diffractometer. FeOOH particles with a diameter range of $0.075-0.3 \mathrm{~mm}$ were used in the experiments. The BET surface area and average pore size of the $\mathrm{FeOOH}$ particles were determined with a surface area and porosity analyzer (ASAP 2020, Micromeritics). The surface density of hydroxyl groups on FeOOH in water was measured according to a saturated deprotonation method (Laiti et al., 1995). The $\mathrm{pH}_{\mathrm{pzc}}$ ( $\mathrm{pH}$ of zero-point surface charge) was measured with a powder addition method (Newcombe et al., 1993). The major properties of the $\mathrm{FeOOH}$ were as follows: $\mathrm{pH}_{\mathrm{pzc}}$ of 7.0, hydroxyl group surface density 
of $0.5 \mathrm{mmol} \mathrm{g}^{-1}$ (in water), specific surface area of $68.4 \mathrm{~m}^{2} \mathrm{~g}^{-1}$, and average pore size of $24 \mathrm{~nm}$.

\subsection{Procedures for ozonation and catalytic ozonation}

Milli-Q water maintained at $16^{\circ} \mathrm{C}$ with circulated cooling water was continuously bubbled with gaseous ozone produced from dried oxygen with an ozone generator (Tongli XFZ-58I, Tsinghua). The aqueous ozone concentration was detected continuously with an ultraviolet spectrometer at $\lambda=258 \mathrm{~nm} \quad\left(\varepsilon=3000 \mathrm{M}^{-1} \mathrm{~cm}^{-1}\right) \quad$ (Elovitz and von Gunten, 1999) until it reached steady state. The steady ozone concentration in water was controlled through adjusting the electric current of the ozone generator. In this study, an aqueous ozone concentration of $10.0 \mathrm{mgL}^{-1}$ was used. About $50 \mathrm{~mL}$ of stock solution of each individual NOM fraction $\left(10 \pm 0.2 \mathrm{mgL}^{-1} \mathrm{DOC}\right)$, which had been pre-adjusted to $\mathrm{pH} 7.0$ with $2 \%(\mathrm{w} / \mathrm{w}) \mathrm{NaOH}$ and $\mathrm{HClO}_{4}$, was quickly mixed with $50 \mathrm{~mL}$ of the ozone-bearing water in a glass reactor. Thus, the initial weight ratio of ozone to DOC in the reaction solution was 1:1. Then, the reactor was sealed and magnetically stirred at a constant temperature of $18{ }^{\circ} \mathrm{C}$ maintained with circulated cooling water. For catalytic ozonation and catalyst adsorption, $100 \mathrm{mgL}^{-1} \mathrm{FeOOH}$ was added into the reactor. The same volume of Milli-Q water was used instead of the ozonebearing water in the case of adsorption tests. The reactions were allowed to proceed for 10 min similar to an ozonation time commonly adopted for pollutants destruction in water treatment plants. $\mathrm{NaSO}_{3}$ solution was used to quench the unreacted ozone in reaction solutions. When UV absorbance was to be determined, the unreacted ozone was stripped off with nitrogen gas. All the samples were filtered through glass fiber filters ( $1 \mu \mathrm{m}$, Whatman) prior to analysis. No buffer was used, because the solution $\mathrm{pH}$ decreased by less than 0.3 units during either ozonation or catalytic ozonation.

\subsection{Analysis}

The concentration of residual ozone after reactions was determined with the indigo method (Bader and Hoigné, 1981). UV absorbance was measured with a spectrophotometer (Model UV-2550, Shimadzu) with the analytical variance of $\pm 0.001 \quad(n=3)$. The concentration of DOC was measured with a Jena 3100 TOC analyzer with the analytical variance of $\pm 0.01 \mathrm{mgL}^{-1}(n=3)$. High-pressure size exclusion chromatography (HP-SEC) was used to characterize MW distribution of the NOM fractions. The HP-SEC system consisted of a gel column (Ultrahydrogel ${ }^{\mathrm{TM}} 250,7.8 \times 300 \mathrm{~mm}$, Waters), a binary pump (Model 1525, Waters), and a UV detector (Model 2487, Waters). Milli-Q water that was buffered with $0.01 \mathrm{M}$ phosphate ( $\mathrm{pH}$ 7.0) was used as the eluent. Operation conditions were as follows: eluent flow rate $0.4 \mathrm{~mL} \mathrm{~min}^{-1}$, injection volume $200 \mu \mathrm{L}$, UV detector wavelength $254 / 220 \mathrm{~nm}$, retention time (RT) $33 \mathrm{~min}$. The correlation between MW and RT was calibrated with polyethylene glycols (Her et al., 2003) (i.e., 20000, 10000, 6000, 1000, and 600 Da) and salicylic acid as standards. A semilog-linear calibration curve was obtained as follows: $\log _{10} \mathrm{MW}=11.556-0.4563 \times \mathrm{RT}$, $R^{2}=0.991$.
Aldehydes and ketones formed in ozonation and catalytic ozonation experiments were derivatized with $0-(2,3,4,5,6-$ pentafluorobenzyl) hydroxylamine hydrochloride (PFBHA, Aldrich) following the USEPA Method 556.1. The derivatives were extracted with methyl tert-butyl ether (MTBE). Qualitative analysis of the derivatives was carried out with a GC/MS (6890N GC/5973 MSD, HP-5 mass column $30 \mathrm{~m} \times 0.25 \mathrm{~mm} \times$ $0.25 \mu \mathrm{m}$, Agilent) in the electron ionization mode as described by Le Lacheur et al. (1993). Quantitative analysis of the derivatives identified by GC/MS was carried out with GC/ ECD $(6890 \mathrm{~N}, \mathrm{HP}-5$ column $30 \mathrm{~m} \times 0.25 \mathrm{~mm} \times 0.25 \mu \mathrm{m}$, Agilent) according to the USEPA Method 556.1.

Ketoacids were first derivitized with PFBHA. The resulting PFBHA oximes were then extracted with MTBE and further silylated to derivatize hydroxyl and carboxylic groups. The silylation was performed with $\mathrm{N}$-(tert-butyldimethylsilyl)- $\mathrm{N}$ methyltrifluoroacetamide containing 1\% tert-butyldimethylchlorosilane as the catalyst (Aldrich). The silylation reagent of $100 \mu \mathrm{L}$ was added into $500 \mu \mathrm{L}$ of the MTBE extract followed by heating at $60^{\circ} \mathrm{C}$ in a water bath for $30 \mathrm{~min}$ (Le Lacheur et al., 1993). Three ketoacids, namely glyoxylic acid, pyruvic acid, and ketomalonic acids, were quantified with GC/MS in the selective ion monitoring mode with $\mathrm{m} / \mathrm{z}$ of 181 and 326 for glyoxylic acid; 181 and 341 for pyruvic acid; and 181 and 427 for ketomalonic acid. The operational conditions of the GC/MS followed Sax et al. (2003). Calibration curves were found to be linear in the ketoacid concentration range from 10 to $300 \mu \mathrm{gL}^{-1}$. Relative standard deviation (RSD) was less than $10 \%$ for each ketoacid of interest.

Carboxylic acids were determined by ion chromatography (Dionex ICS-3000, IonPac AS-11 analytical column, and conductivity detector). The eluent was $30 \mathrm{mM} \mathrm{KOH}$ solution at a flow rate of $1.2 \mathrm{~mL} \mathrm{~min}^{-1}$. The injection volume was $50 \mu \mathrm{L}$. All analyses were performed at a constant temperature of $25^{\circ} \mathrm{C}$. Calibration curves were found to be linear in the carboxylic acid concentration range from 50 to $500 \mu \mathrm{gL}^{-1}$ with RSD less than $10 \%$ for each carboxylic acid of interest.

\section{Results and discussion}

\subsection{Ozone consumption and changes of DOC and UV absorbance}

The decay of aqueous ozone concentration during ozonation and catalytic ozonation of each individual NOM fraction is shown in Fig. 1. Results indicate that catalytic ozonation notably enhances the ozone consumption rate compared to ozonation alone during oxidation of the NOM fractions. Lim et al. (2001) found that a commercial goethite could enhance ozone decomposition in pure water and consequently promote hydroxyl radical generation. Kasprzyk-Hordern et al. (2006) proposed that aqueous ozone could be concentrated into the NOM layers that were absorbed on the surface of metal oxides due to the hydrophobic nature of the NOM layer and the relatively non-polar nature of ozone. Similarly, the increased ozone consumption rate in catalytic ozonation could be ascribed to either or both of the above reaction mechanisms. 
The reduction percentages of DOC and $\mathrm{UV}_{254}$ absorbance of the individual NOM fractions after $\mathrm{FeOOH}$ adsorption, ozonation, and catalytic ozonation are shown in Table 1. Results indicate that a certain portion of these fractions, ranging from $4.2 \%$ to $10.2 \%$, can be adsorbed on the $\mathrm{FeOOH}$ surface. Catalytic ozonation reduces the DOC more effectively than ozonation alone for HIA and HIB, but has much less effect on the DOC reduction for HOA and HON. For HIA and HIB, the DOC reduction in catalytic ozonation notably exceeds the overall DOC reduction in $\mathrm{FeOOH}$ adsorption and ozonation. This result indicates that the enhanced DOC reduction in the catalytic ozonation is not simply due to surface adsorption by FeOOH. The higher DOC reductions for HIA and HIB than that for HOA and HON in the catalytic ozonation is likely due to the difference in hydrophobicity of the adsorbed fractions on $\mathrm{FeOOH}$. Because of its strong hydrophobicity, the adsorbed HOA or HON layer can attract more ozone than the HIA or HIB layer that is rich in hydroxyl groups (Leenheer, 1981). Therefore, in catalytic ozonation of the hydrophilic fractions, more aqueous ozone may be decomposed by $\mathrm{FeOOH}$ to produce hydroxyl radicals which are more efficient in mineralizing organic oxidation products than molecular ozone (von Gunten, 2003).

Results also show that ozonation alone can significantly reduce $\mathrm{UV}_{254}$ for all the individual NOM fractions (Table 1), and catalytic ozonation further improves the reduction of

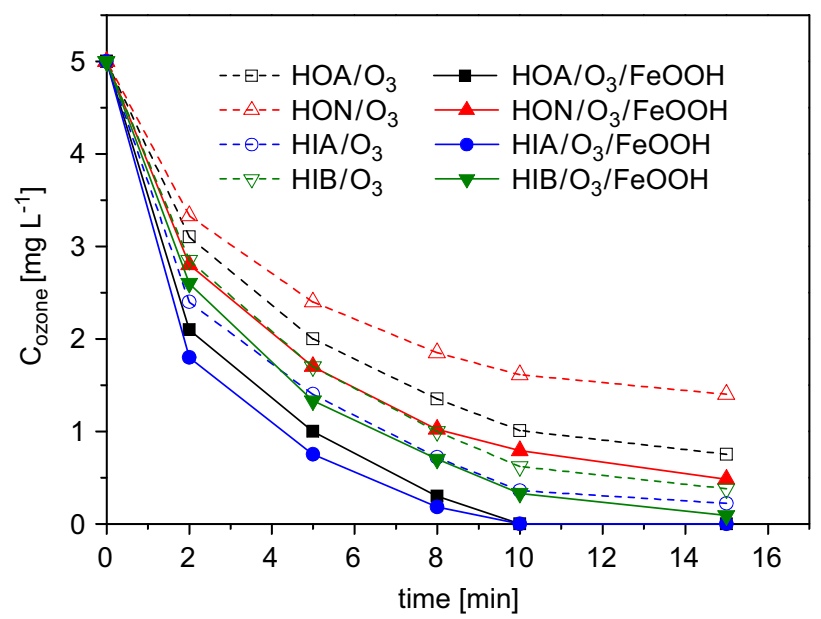

Fig. 1 - Changes of aqueous ozone concentration during ozonation and catalytic ozonation of individual NOM fractions.
$\mathrm{UV}_{254}$. FeOOH adsorption only contributes a slight decrease of $\mathrm{UV}_{254}$ ranging from $3.0 \%$ to $7.4 \%$. It is known that $\mathrm{UV}_{254}$ represents the content of aromatic structures and double bonds of NOM. The effective destruction of these unsaturated structures in ozonation alone is clearly due to the electrophilic attack of ozone. Catalytic ozonation improves the $\mathrm{UV}_{254}$ reduction due to the enhanced generation of hydroxyl radicals as well as the enhanced local reactions between NOM fractions and molecular ozone in the adsorbed surface NOM layer.

\subsection{Molecular weight (MW) distribution}

The MW distribution pattern of individual NOM fractions after FeOOH adsorption, ozonation, and catalytic ozonation is shown in Figs. 2a and b. The HP-SEC spectra here only show the MW higher than $300 \mathrm{Da}$, because the spectra of those lower-MW overlap with the peak of sulfite that was used to quench residual ozone in reaction solution. The HP-SEC spectra were measured at both 254 and $220 \mathrm{~nm}$. Compared with the $254 \mathrm{~nm}$ spectra, the $220 \mathrm{~nm}$ spectra can denote the formation of low-MW oxidation by-products without aromatic structures (Świetlik et al., 2004).

As revealed in Fig. 2a, the adsorption of all the individual NOM fractions onto FeOOH surface is relatively insignificant, which agrees well with the results shown in Table 1 . The components of each NOM fraction, with MW approximately ranging from 1000 to $10000 \mathrm{Da}$, exhibit a higher affinity to FeOOH than other components out of this MW range if examined at $254 \mathrm{~nm}$. However, the $\mathrm{UV}_{220}$ spectra (Fig. 2b) reveal that a portion of low-MW components, which respond weakly to $\mathrm{UV}_{254}$, can also get adsorbed onto $\mathrm{FeOOH}$ surface to some extent. Thus, FeOOH preferentially adsorbs two parts of each NOM fraction: one with MW ranging from 1000 to $10000 \mathrm{Da}$ and rich in aromatic rings and double bonds, and the other with MW lower than $1000 \mathrm{Da}$ and lacking aromatic and double bond structures.

Ozonation causes significant fragmentation of the highMW (>3000 Da) components for each individual NOM fraction and alters the MW distribution towards smaller molecules (Fig. 2a). Catalytic ozonation further promotes the fragmentation of these high-MW ( $>3000 \mathrm{Da}$ ) components. With regard to low-MW oxidation products of weak $\mathrm{UV}_{254}$ response, catalytic ozonation increases their percentage in the MW range of about $400-900 \mathrm{Da}$ for each NOM fraction, which is similar to the case in ozonation alone (Fig. 2b). The formation

Table 1 - Reduction of DOC and $\mathbf{U V}_{254}$ absorbance by ozonation, catalytic ozonation, and FeOOH adsorption

\begin{tabular}{|c|c|c|c|c|c|c|}
\hline \multirow[t]{2}{*}{ NOM fraction } & \multicolumn{3}{|c|}{ DOC reduced (\%) } & \multicolumn{3}{|c|}{$\mathrm{UV}_{254}$ reduced (\%) } \\
\hline & $\mathrm{FeOOH}$ & $\mathrm{O}_{3}$ & $\mathrm{O}_{3} / \mathrm{FeOOH}$ & $\mathrm{FeOOH}$ & $\mathrm{O}_{3}$ & $\mathrm{O}_{3} / \mathrm{FeOOH}$ \\
\hline HOA & $4.2 \pm 1.5$ & $5.2 \pm 3.6$ & $10.2 \pm 1.2$ & $3.0 \pm 1.0$ & $45.5 \pm 2.2$ & $48.3 \pm 1.8$ \\
\hline HON & $10.2 \pm 2.2$ & $2.1 \pm 1.8$ & $15.5 \pm 1.2$ & $4.2 \pm 2.0$ & $41.7 \pm 4.2$ & $66.7 \pm 3.0$ \\
\hline HIA & $10.1 \pm 3.0$ & $0.4 \pm 0.4$ & $25.0 \pm 1.8$ & $7.4 \pm 2.2$ & $46.9 \pm 2.0$ & $51.4 \pm 2.5$ \\
\hline HIB & $5.5 \pm 1.2$ & $6.5 \pm 5.7$ & $30.9 \pm 2.4$ & $4.5 \pm 1.2$ & $41.1 \pm 2.0$ & $56.3 \pm 2.7$ \\
\hline
\end{tabular}


a
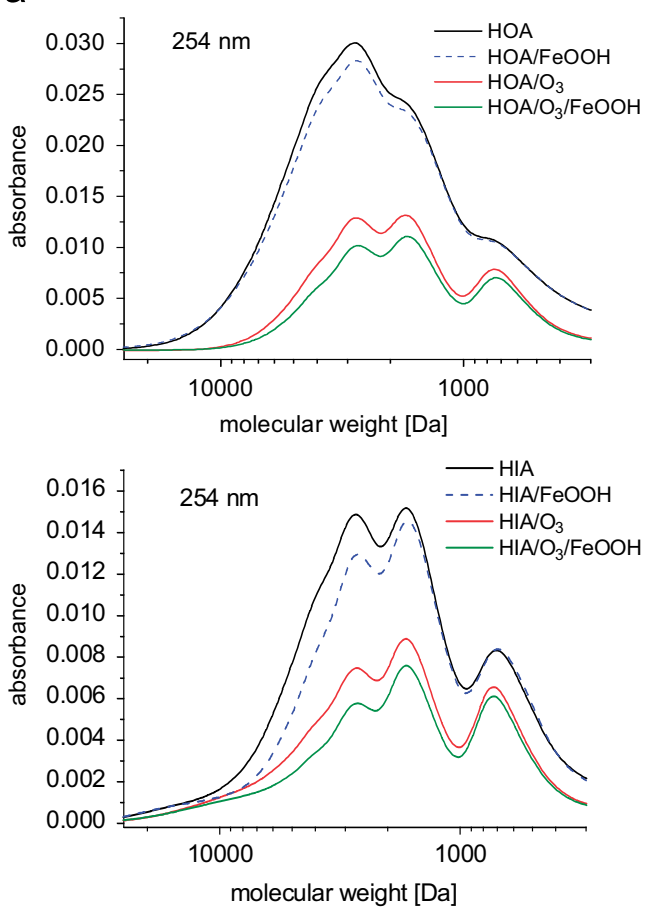

b
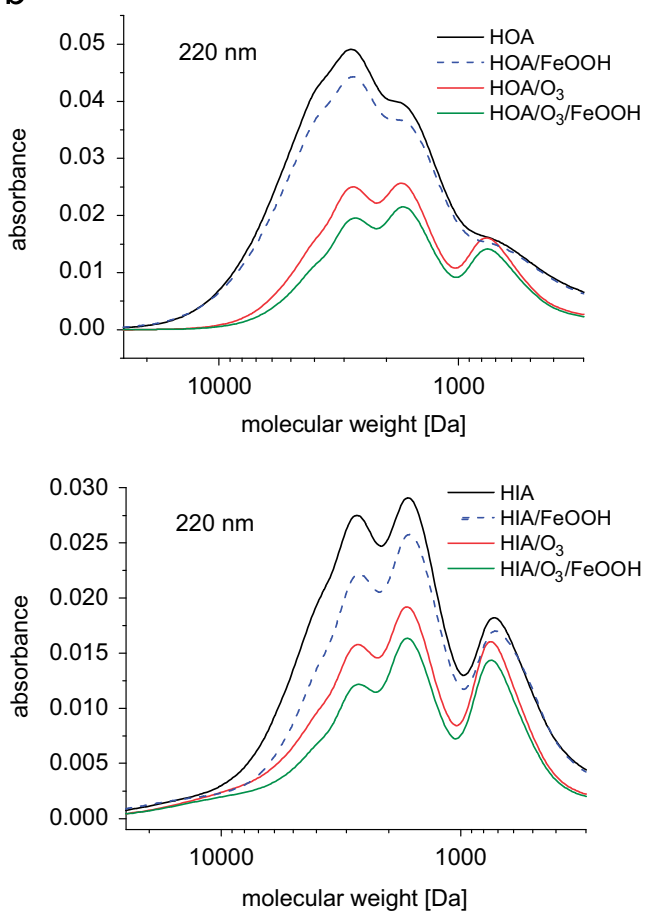
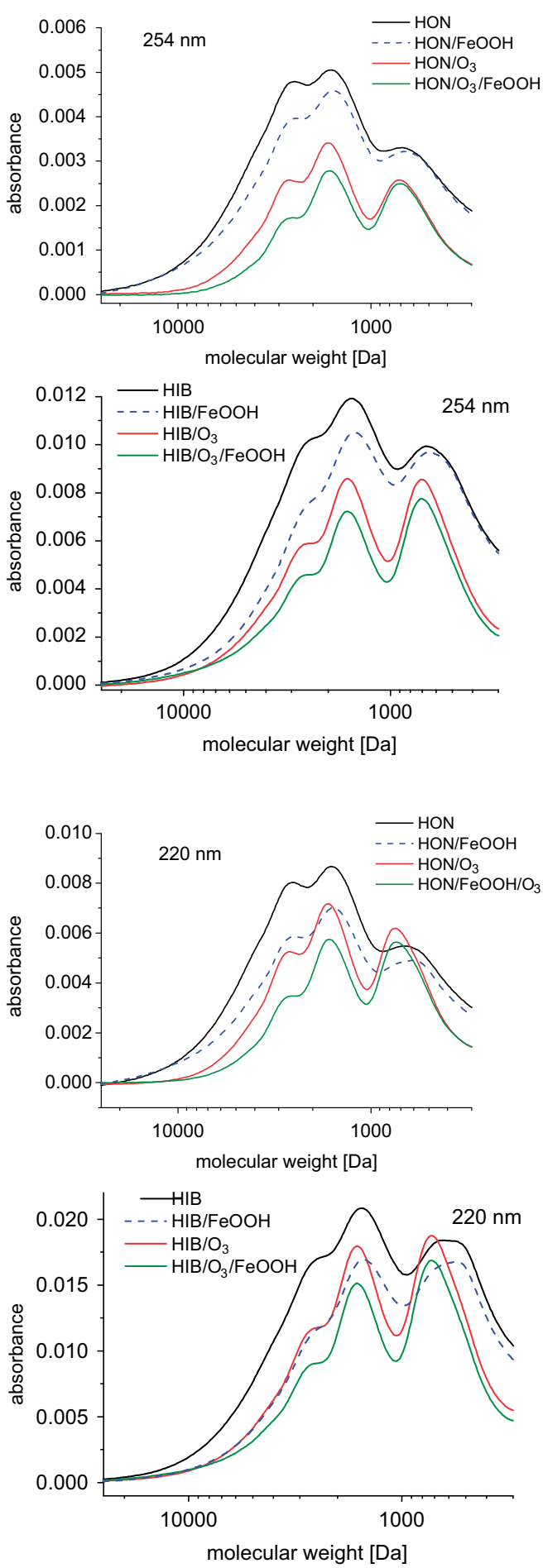

Fig. 2 - Molecular weight distribution of individual NOM fractions after FeOOH adsorption, ozonation, and catalytic ozonation measured at $\lambda=254 \mathrm{~nm}$ (a) and $220 \mathrm{~nm}$ (b).

of oxidation products with even lower MW (<300 Da) was observed by means of other chromatography methods. This will be discussed later in this work.

Besides the changes in the MW distribution, Figs. 2a and b also show the UV absorbance decrease of the NOM fractions along their MW ranges in ozonation and catalytic ozonation. Ozonation significantly reduces the $\mathrm{UV}_{254}$ for the fraction components throughout their MW ranges (300-10000 Da). Catalytic ozonation further improves the $\mathrm{UV}_{254}$ reduction for the components with $\mathrm{MW}>1000 \mathrm{Da}$, but has much less effect on the $\mathrm{UV}_{254}$ reduction for lower-MW components. However, the catalytic ozonation does improve the $\mathrm{UV}_{220}$-absorbance reduction for the fraction components with $\mathrm{MW}<1000 \mathrm{Da}$ compared with ozonation alone (Fig. 2b), implying that the 
catalytic ozonation can also promote the destruction of the weak $\mathrm{UV}_{254}$-response structures of the low-MW components.

\subsection{Oxidation by-products}

The oxidation by-products with low MWs (<300 Da) were identified and then quantified with GC/MS, GC/ECD, and IC for each individual NOM fraction. The identified aldehydes and ketones include formaldehyde, acetaldehyde, glyoxal, methyl glyoxal, and acetone. Aldehydes are of health concern, and are the common surrogates of a large number of polar organic by-products formed in ozonation treatment (Weinberg et al., 1993). Other major by-products identified in this study include three ketoacids (i.e., glyoxylic, pyruvic, and ketomalonic acids) and two carboxylic acids (i.e., formic and oxalic acids). These oxidation by-products are more biodegradable than their precursors, thus probably raising the risk of microbial regrowth in water distribution systems (Gagnon et al., 1997; Griffini et al., 1999; DiGiano et al., 2001).

The yields of aldehydes and acetone after ozonation and catalytic ozonation of individual NOM fractions are summarized in Table 2. The yields of these by-products (especially that of formaldehyde) after ozonation are much higher than those reported by Glaze et al. (1989), Paode et al. (1997), and Świetlik et al. (2004). Their lower yields are possibly due to the experimental mode of continuously bubbling of gaseous ozone into the reaction solutions, which would strip off a portion of the volatile aldehydes and acetone. Results show that both ozonation and catalytic ozonation produce a considerably higher yield of total aldehydes and acetone from hydrophobic fractions (i.e., HOA and HON) than from hydrophilic fractions (i.e., HIA and HIB). Compared with ozonation alone, catalytic ozonation produces a similar yield of total aldehydes and acetone from HOA and HON, while it notably increases the yield of total aldehydes and acetone from HIA and HIB by about 17 and 41\%, respectively.

The yields of ketoacids and carboxylic acids after ozonation and catalytic ozonation of individual NOM fractions are summarized in Tables 3 and 4, respectively. Results indicate that for HOA, HON, and HIA, the catalytic ozonation produces less total ketoacids (Table 3 ) and more total carboxylic acids (Table 4) than ozonation. For HIB, however, the yields of total ketoacids and total carboxylic acids after catalytic ozonation are similar to those after ozonation alone. It is noted that the catalytic ozonation produces more oxalic acid than ozonation alone for all the individual NOM fractions. According to Edwards and Benjamin (1992), oxalic acid is usually one of the dominant final by-products in the ozonation of NOM. Further oxidation of the reaction intermediates or by-products such as glyoxal, glyoxylic acid, and pyruvic acid also leads to the formation of oxalic acid (Caprio et al., 1987, 1989; Rivas et al., 2006). The oxalic acid is almost least reactive towards ozone and hydroxyl radicals among these oxidation by-products (Hoigné and Bader, 1983a, 1983b; von Gunten, 2003). Therefore, the enhanced accumulation of oxalic acid in the catalytic ozonation implies an enhanced oxidation of the NOM fractions in comparison to ozonation alone.

According to former researches (Gagnon et al., 1997; Griffini et al., 1999; DiGiano et al., 2001), all of these oxidation byproducts are readily biodegradable. Schechter and Singer (1995) showed a correlation between aldehydes and assimilable organic carbon (AOC). A correlation between AOC and ketoacids has also been reported (Melin and Ødegaard, 2000). Griffini et al. (1999) observed a relationship between the biodegradable DOC and the sum of aldehydes and ketoacids. More recently, Hammes et al. (2006) found that organic acids

Table 2 - Yields of aldehydes and acetone after ozonation and catalytic ozonation of individual NOM fractions

\begin{tabular}{|c|c|c|c|c|c|c|c|c|c|c|c|c|}
\hline \multirow[t]{2}{*}{$\begin{array}{l}\text { NOM } \\
\text { fraction }\end{array}$} & \multicolumn{2}{|c|}{$\begin{array}{l}\text { Formaldehyde } \\
\qquad\left(\mu \mathrm{gL}^{-1}\right)\end{array}$} & \multicolumn{2}{|c|}{$\begin{array}{l}\text { Acetaldehyde } \\
\qquad\left(\mu \mathrm{gL}^{-1}\right)\end{array}$} & \multicolumn{2}{|c|}{ Glyoxal $\left(\mu \mathrm{gL}^{-1}\right)$} & \multicolumn{2}{|c|}{$\begin{array}{l}\text { Methyl glyoxal } \\
\left(\mu g L^{-1}\right)\end{array}$} & \multicolumn{2}{|c|}{ Acetone $\left(\mu g L^{-1}\right)$} & \multicolumn{2}{|c|}{$\begin{array}{c}\text { Total aldehydes and } \\
\text { acetone }\left(\mu \mathrm{gL}^{-1}\right)\end{array}$} \\
\hline & $\mathrm{O}_{3}$ & $\begin{array}{c}\mathrm{O}_{3} / \\
\mathrm{FeOOH}\end{array}$ & $\mathrm{O}_{3}$ & $\begin{array}{c}\mathrm{O}_{3} / \\
\mathrm{FeOOH}\end{array}$ & $\mathrm{O}_{3}$ & $\begin{array}{c}\mathrm{O}_{3} / \\
\mathrm{FeOOH}\end{array}$ & $\mathrm{O}_{3}$ & $\begin{array}{c}\mathrm{O}_{3} / \\
\mathrm{FeOOH}\end{array}$ & $\mathrm{O}_{3}$ & $\begin{array}{c}\mathrm{O}_{3} / \\
\mathrm{FeOOH}\end{array}$ & $\mathrm{O}_{3}$ & $\begin{array}{c}\mathrm{O}_{3} / \\
\mathrm{FeOOH}\end{array}$ \\
\hline $\mathrm{HOA}$ & $202 \pm 5$ & $189 \pm 4$ & $23 \pm 2$ & $23 \pm 2$ & $42 \pm 2$ & $45 \pm 2$ & $45 \pm 2$ & $48 \pm 2$ & $36 \pm 2$ & $39 \pm 2$ & $348 \pm 13$ & $345 \pm 12$ \\
\hline HON & $279 \pm 7$ & $274 \pm 7$ & $17 \pm 2$ & $15 \pm 1$ & $55 \pm 2$ & $58 \pm 2$ & $70 \pm 2$ & $67 \pm 2$ & $57 \pm 2$ & $47 \pm 2$ & $478 \pm 15$ & $461 \pm 14$ \\
\hline HIA & $169 \pm 3$ & $179 \pm 3$ & $21 \pm 2$ & $26 \pm 2$ & $41 \pm 2$ & $49 \pm 2$ & $38 \pm 2$ & $50 \pm 2$ & $18 \pm 2$ & $20 \pm 2$ & $289 \pm 11$ & $340 \pm 11$ \\
\hline HIB & $52 \pm 2$ & $70 \pm 2$ & $17 \pm 1$ & $29 \pm 2$ & $36 \pm 2$ & $46 \pm 2$ & $2.5 \pm 1$ & $16 \pm 1$ & $24 \pm 2$ & $27 \pm 2$ & $132 \pm 8$ & $187 \pm 9$ \\
\hline
\end{tabular}

Table 3 - Yields of ketoacids after ozonation and catalytic ozonation of individual NOM fractions

\begin{tabular}{|c|c|c|c|c|c|c|c|c|}
\hline \multirow[t]{2}{*}{ NOM fraction } & \multicolumn{2}{|c|}{ Glyoxylic acid $\left(\mu \mathrm{gL}^{-1}\right)$} & \multicolumn{2}{|c|}{ Pyruvic acid $\left(\mu \mathrm{gL}^{-1}\right)$} & \multicolumn{2}{|c|}{ Ketomalonic $\left(\mu \mathrm{gL}^{-1}\right)$} & \multicolumn{2}{|c|}{ Total ketoacids $\left(\mu g L^{-1}\right)$} \\
\hline & $\mathrm{O}_{3}$ & $\mathrm{O}_{3} / \mathrm{FeOOH}$ & $\mathrm{O}_{3}$ & $\mathrm{O}_{3} / \mathrm{FeOOH}$ & $\mathrm{O}_{3}$ & $\mathrm{O}_{3} / \mathrm{FeOOH}$ & $\mathrm{O}_{3}$ & $\mathrm{O}_{3} / \mathrm{FeOOH}$ \\
\hline $\mathrm{HOA}$ & $37 \pm 2$ & $35 \pm 3$ & $214 \pm 2$ & $203 \pm 2$ & $16 \pm 4$ & $11 \pm 6$ & $267 \pm 8$ & $249 \pm 11$ \\
\hline $\mathrm{HON}$ & $24 \pm 2$ & $17 \pm 4$ & $362 \pm 6$ & $305 \pm 4$ & $14 \pm 5$ & $11 \pm 6$ & $400 \pm 13$ & $333 \pm 14$ \\
\hline HIA & $48 \pm 3$ & $35 \pm 2$ & $153 \pm 4$ & $123 \pm 2$ & $18 \pm 7$ & $10 \pm 5$ & $219 \pm 14$ & $168 \pm 9$ \\
\hline HIB & $27 \pm 2$ & $23 \pm 2$ & $25 \pm 5$ & $35 \pm 4$ & $15 \pm 6$ & $14 \pm 6$ & $67 \pm 13$ & $72 \pm 12$ \\
\hline
\end{tabular}


Table 4 - Yields of carboxylic acids after ozonation and catalytic ozonation of individual NOM fractions

\begin{tabular}{|c|c|c|c|c|c|c|}
\hline \multirow[t]{2}{*}{ NOM fraction } & \multicolumn{2}{|c|}{ Formic acid $\left(\mu g L^{-1}\right)$} & \multicolumn{2}{|c|}{ Oxalic acid $\left(\mu g \mathrm{~L}^{-1}\right)$} & \multicolumn{2}{|c|}{ Total carboxylic acids $\left(\mu \mathrm{gL}^{-1}\right)$} \\
\hline & $\mathrm{O}_{3}$ & $\mathrm{O}_{3} / \mathrm{FeOOH}$ & $\mathrm{O}_{3}$ & $\mathrm{O}_{3} / \mathrm{FeOOH}$ & $\mathrm{O}_{3}$ & $\mathrm{O}_{3} / \mathrm{FeOOH}$ \\
\hline $\mathrm{HOA}$ & $404 \pm 11$ & $470 \pm 10$ & $307 \pm 7$ & $329 \pm 8$ & $711 \pm 17$ & $799 \pm 18$ \\
\hline HON & $332 \pm 11$ & $343 \pm 12$ & $209 \pm 6$ & $248 \pm 5$ & $541 \pm 17$ & $591 \pm 17$ \\
\hline HIA & $364 \pm 12$ & $366 \pm 15$ & $282 \pm 5$ & $310 \pm 6$ & $646 \pm 17$ & $676 \pm 21$ \\
\hline HIB & $494 \pm 18$ & $470 \pm 14$ & $214 \pm 6$ & $234 \pm 4$ & $708 \pm 24$ & $704 \pm 18$ \\
\hline
\end{tabular}

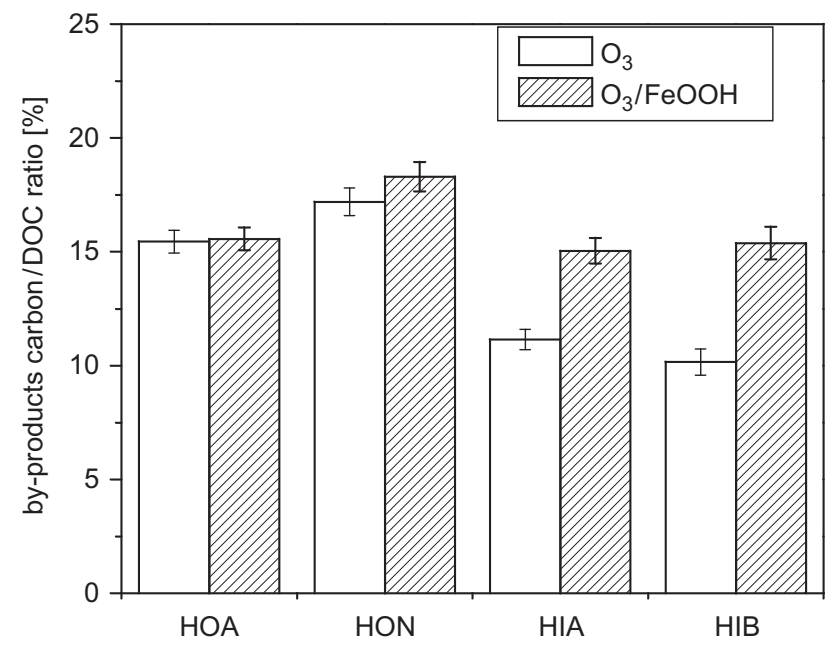

Fig. 3 - Ratio of identified by-products carbon content to the final DOC of individual NOM fractions after ozonation and catalytic ozonation. Error bars represent the standard deviation of triplicate experiments.

constituted a large fraction of newly formed AOC after ozonation. In this study, the total organic carbon contained in all these by-products was summed up for each individual NOM fraction. Its ratio to the final DOC of the NOM fraction was then regarded as an indicator of the biodegradability after ozonation or catalytic ozonation. As shown in Fig. 3, the oxidation by-products occupy about $17.2 \%$ and $18.3 \%$ of the final DOC of HON after ozonation and catalytic ozonation, respectively. They are the highest percentages among the oxidized NOM fractions, and are statistically of no difference. In addition, the catalytic ozonation produces a similar percentage of oxidation by-products, expressed in the DOC ratio, to ozonation alone for HOA. However, the DOC ratios for HIA and HIB after catalytic ozonation are $4 \%$ and $5 \%$ higher than those after ozonation alone, respectively. Since the contents of HOA (49.6\%) and HON (46.1\%) are much higher than those of HIA (2.5\%) and HIB (1.2\%) in the filtered water, the catalytic ozonation does not seem to notably change the total biodegradability of the treated water compared to ozonation alone under normal conditions applied in water treatment plants. Therefore, similar to ozonation alone, the catalytic ozonation also requires a follow-up bio-filtration process to further remove the oxidation by-products to ensure the microbial stability in water distribution systems.

\section{Conclusion}

This work investigated the impact of synthetic goethitecatalyzed ozonation on four major NOM fractions isolated from the filtered water of a water treatment plant, while ozonation alone was carried out as comparison experiments. Results indicate that the catalytic ozonation can improve the ozone consumption rate, DOC removal efficiency (especially for HIA and HIB), and the destruction of aromatic and double bond structures compared with ozonation alone. In addition, the catalytic ozonation can more effectively fragment the high-MW components ( $>3000 \mathrm{Da}$ ) of NOM fractions, and destruct the UV-absorbing structures throughout the MW range of $300-10000 \mathrm{Da}$ than ozonation alone. Meanwhile, both catalytic ozonation and ozonation promote the formation of weak $\mathrm{UV}_{254}$-response components in the MW range of $400-900 \mathrm{Da}$ for the NOM fractions.

The catalytic ozonation produces more aldehydes from HIA and HIB, and more oxalic acid from all the individual NOM fractions than ozonation under identical experimental conditions. In comparison to ozonation alone, the catalytic ozonation enhances the ratio of the readily biodegradable organic carbon to the final DOC for HIA and HIB, while does not enhance that ratio for HOA and HON. Bio-filtration is thus proposed to follow the catalytic ozonation to ensure the microbial stability in water distribution systems.

\section{Acknowledgment}

The authors greatly appreciate the financial support from National Natural Science Foundation of China (Project no. 50578051).

\section{R E F E R E N C E S}

Bader, H., Hoigné, J., 1981. Determination of ozone in water by the indigo method. Water Res. 15, 449-456.

Beltrán, F.J., Rivas, F.J., Montero-de-Espinosa, R., 2005. Iron type catalysts for the ozonation of oxalic acid in water. Water Res. 39, 3553-3564.

Caprio, V., Insola, A., Silvestre, A.M., 1987. Ozonation of glyoxylic acid in aqueous solution: chemical products and kinetics evolution. Ozone Sci. Engi. 9, 13-22.

Caprio, V., Insola, A., Silvestre, A.M., 1989. Glyoxal ozonation process in aqueous solution. Ozone Sci. Engi. 11, 271-280. 
DiGiano, F.A., Singer, P.C., Parameswar, C., LeCourt, T.D., 2001. Biodegradation kinetics of ozonated NOM and aldehydes. J. Am. Water Works Assoc. 93 (8), 92-104.

Edwards, M., Benjamin, M.M., 1992. Transformation of NOM by ozone and its effect on iron and aluminum solubility. J. Am. Water Works Assoc. 84 (6), 56-66.

Elovitz, M.S., von Gunten, U., 1999. Hydroxyl radical/ozone ratios during ozonation processes. I. The Rct concept. Ozone Sci. Engi. 21, 239-260.

Gagnon, G.A., Booth, S.D.J., Peldszus, S., Mutti, D., Smith, F., Huck, P.M., 1997. Carboxylic acids: formation and removal in fullscale plants. J. Am. Water Works Assoc. 89 (8), 88-97.

Glaze, W.H., Koga, M., Cancilla, D., 1989. Ozonation byproducts. 2. Improvement of an aqueous-phase derivatization method for the detection of formaldehyde and other carbonyl compounds formed by the ozonation of drinking water. Environ. Sci. Technol. 23, 838-847.

Gracia, R., Cortes, S., Sarasa, J., Ormad, P., Ovelleiro, J.L., 2000. $\mathrm{TiO}_{2}$-catalysed ozonation of raw Ebro river water. Water Res. 34, 1525-1532.

Griffini, O., Bao, M.L., Barbieri, K., Burrini, D., Santianni, D., Pantani, F., 1999. Formation and removal of biodegradable ozonation by-products during ozonation-biofiltration treatment: pilot-scale evaluation. Ozone Sci. Engi. 21, 79-98.

Hammes, F., Salhi, E., Köster, O., Kaiser, H.P., Egli, T., von Gunten, U., 2006. Mechanistic and kinetic evaluation of organic disinfection by-product and assimilable organic carbon (AOC) formation during the ozonation of drinking water. Water Res. 40, 2275-2286.

Her, N., Amy, G., McKnight, D., Sohn, J., Yoon, Y., 2003. Characterization of DOM as a function of MW by fluorescence EEM and HPLC-SEC using UVA, DOC, and fluorescence detection. Water Res. 37, 4295-4303.

Hoigné, J., Bader, H., 1983a. Rate constants of reactions of ozone with organic and inorganic compounds in water-1. Water Res. 17, 173-183.

Hoigné, J., Bader, H., 1983b. Rate constants of reactions of ozone with organic and inorganic compounds in water-2. Water Res. 17, 185-194.

Kandori, K., Fukuoka, M., Ishikawa, T., 1991. Effects of citrate ion on the formation of ferric oxide hydroxide particles. J. Material Sci. 26, 3313-3319.

Kasprzyk-Hordern, B., Ziolek, M., Nawrocki, J., 2003. Catalytic ozonation and methods of enhancing molecular ozone reactions in water treatment. Appl. Catal. B-Environ. 46, 639-669.

Kasprzyk-Hordern, B., Raczyk-Stanislawiak, U., Świetlik, J., Nawrocki, J., 2006. Catalytic ozonation of natural organic matter on alumina. Appl. Catal. B-Environ. 62, 345-358.

Korshin, G.V., Benjamin, M.M., Sletten, R.S., 1997. Adsorption of natural organic matter (NOM) on iron oxide: effects on NOM composition and formation of organo-halide compounds during chlorination. Water Res. 31, 1643-1650.

Laiti, E., Öhman, L.O., Nordin, J., Sjöberg, S., 1995. Acid/base properties and phenylphosphonic acid complexation at the aged $\gamma-\mathrm{Al}_{2} \mathrm{O}_{3} /$ water interface. J. Colloid Interface Sci. 175, 230-238.

Leenheer, J.A., 1981. Comprehensive approach to preparative isolation and fractionation of dissolved organic carbon from natural water and wastewaters. Environ. Sci. Technol. 15, 578-587.

Le Lacheur, R.M., Sonnenberg, L.B., Singer, P.C., Christman, R.F., Charles, M.J., 1993. Identification of carbonyl compounds in environmental samples. Environ. Sci. Technol. 27, 2745-2753.

Lim, H.N., Choi, H., Hwang, T.M., Kang, J.W., 2001. Characterization of ozone decomposition in a soil slurry: kinetics and mechanism. Water Res. 36, 219-229.

Ma, J., Graham, N.J.D., 2000. Degradation of atrazine by manganese-catalysed ozonation-influence of radical scavengers. Water Res. 34, 3822-3828.

Melin, E.S., Ødegaard, H., 2000. The effect of biofilter loading rate on the removal of organic ozonation by-products. Water Res. $34,4464-4476$.

Newcombe, G., Hayes, R., Drikas, M., 1993. Granular activated carbon: importance of surface properties in the adsorption of naturally occurring organics. Colloid Surf. A 78, 65-71.

Paode, R.D., Amy, S.W., Summers, R.S., Rice, E.W., 1997. Predicting the formation of aldehydes and BOM. J. Am. Water Works Assoc. 89 (6), 79-93.

Park, J.S., Choi, H., Cho, J., 2004a. Kinetic decomposition of ozone and para-chlorobenzoic acid (pCBA) during catalytic ozonation. Water Res. 38, 2285-2292.

Park, J.S., Choi, H.C., Ahn, K.H., Kang, J.W., 2004b. Removal mechanism of natural organic matter and organic acid by ozone in the presence of goethite. Ozone Sci. Engi. 26, 141-151.

Rivas, F.J., Carbajo, M., Beltran, F.J., Acedo, B., Gimeno, O., 2006. Perovskite catalytic ozonation of pyruvic acid in water: operating conditions influence and kinetics. Appl. Catal. B-Environ. 62, 93-103.

Sax, M., Kalberer, M., Zenobi, R., 2003. Sampling gaseous oxidation products of aromatic compounds in gas/particle separation systems. J. Environ. Monit. 5, 103-107.

Schechter, D.S., Singer, P.C., 1995. Aldehydes formation during ozonation. Ozone Sci. Engi. 17, 53-59.

Singer, P.C., 1999. Humic substances as precursors for potentially harmful disinfection by-products. Water Sci. Technol. 40 (9), 25-30.

Świetlik, J., Dabrowska, A., Raczyk-Stanislawiak, U., Nawrocki, J., 2004. Reactivity of natural organic matter fractions with chlorine dioxide and ozone. Water Res. 38, 547-558.

von Gunten, U., 2003. Ozonation of drinking water: Part I. Oxidation kinetics and product formation. Water Res. 37, 1443-1467.

Weinberg, H.S., Glaze, W.H., Krasner, S.W., Sclimenti, M.J., 1993. Formation and removal of aldehydes in plants that use ozonation. J. Am. Water Works Assoc. 85 (5), 72-85.

Zhang, T., Ma, J., 2007. Catalytic ozonation of trace nitrobenzene in water with synthetic goethite. J. Mol. Catal. A-Chem., in press, doi:10.1016/j.molcata.2007.09.030. 